\title{
The Denver Tube Combined with Antiviral Drugs In the Treatment of HBV-related Cirrhosis with Refractory Ascites: A Report of Three Cases
}

\author{
Xiao-jin Wang, Li-qin Shi, Qing-chun Fu, Liu-da Ni, Feng Zhou, Jin-wei Chen and Cheng-wei Chen
}

Treatment of nucleos(t)ide antiviral drugs for decompensated HBV-related cirrhosis can significantly improve the prognosis. But those patients with refractory ascites possibly deteriorate due to the complications of ascites before any benefit from anti-viral drugs could be observed. Therefore, it is important to find a way to help the patients with HBV-related cirrhosis and refractory ascites to receive the full benefits from antiviral therapy. Peritoneovenous shunt (PVS) using Denver tube enables ascites to continuously bypass into systemic circulation, thereby reducing ascites and albumin input and improving quality of life. We report herein 3 cases of decompensated HBV-related cirrhosis with refractory ascites, PVS using Denver tube was combined with lamivudine for antiviral treatment before and after. Then, ascites was alleviated significantly or disapeared and viral responsed well. All patients achieved a satisfactory long-term survival from 6.7 to 14.7 years. It was suggested that the Denver shunt could be used as an adjuvant method to antiviral drugs for decompensated HBV-related cirrhosis with refractory ascites to help the patients reap the full benefits and maximize efficacy of antiviral treatment.

Key words: Cirrhosis, decompensation; Ascites; Denver tube; Nucleos(t)ide analogue

$\mathrm{R}$ efractory ascites is defined by the International Ascites Club as ascites that cannot be mobilized or the early recurrence of which (i.e., after therapeutic paracentesis) cannot be satisfactorily prevented by medical therapy. ${ }^{1}$ Cirrhosis with refractory ascites remains a serious clinical problem. If ascites can not be controlled effectively, the patient ends up with poor quality of life and poor prognosis, with a mortality rate reaching as high as $75 \%$ after one year. Nucleos(t)ide antiviral drugs for decompensated HBV-related cirrhosis can significantly improve prognosis and delay or avoid liver transplantation, with a 3-year survival rate of over $80 \%$. During the early stages of medication, viruses were effectively inhibited, however there was little change in the patient's condition. In the case of patients with refractory ascites, it is not likely that their clinical conditions (e.g. spontaneous bacterial peritonitis or hepatorenal syndrome) would improve before any benefit from anti-viral drugs Correspondence: Qing-chun Fu, Email:qcfu85@163.com Shanghai Liver Disease Research Center; Nanjing Military Command, Shanghai 200235, China could be observed. ${ }^{2}$ Therefore, it is necessory to place importance on finding a novel way to help patients with HBV-related cirrhosis and refractory ascites to receive the full benefits from antiviral treatments. In this article, the long-term survival data after peritoneovenous shunt (PVS) using Denver tube combined with antiviral drugs in 3 cases with HBVrelated cirrhosis and refractory ascites were reported.

\section{CASE REPORT}

Case 1: 2 months of antiviral therapy followed by PVS

A 46-year-old male patient was admitted to hospital with cirrhotic ascites in December, 2006. This condition was present for about 6 years but more recently became aggravated for 4 months. $\mathrm{HBsAg}$ was positive, $\mathrm{HBeAg}$ was negative, serum HBV DNA was $2.39 \times 10^{5}$ copies $/ \mathrm{ml}$, $\mathrm{B}$ ultrasound showed cirrhosis with massive ascites, CTP score was 11 points and MELD score was 12 points. The patient was given lamivudine for antiviral treatment. Two months later, the serum HBV DNA was $<1 \times 10^{3}$ 
copies $/ \mathrm{ml}$. Despite a sodium-restricted diet and intensive diuretic treatment, ascites was not well controlled and paracentesis was carried out for 1.6 times each week on average. The abdominal circumference was 90 $\mathrm{cm}$ and urinary volume was $700 \mathrm{ml} / \mathrm{d}$. Subsequently, peritoneovenous shunt (PVS) using Denver tube was performed. After surgery, urinary volume increased to $2000 \mathrm{ml} / \mathrm{d}$, and abdominal distension improved significantly. Two weeks later, abdominal circumference decreased to $80 \mathrm{~cm}$ and body weight was reduced by 4 $\mathrm{kg}$. Then, diuretics were maintained in small amount, lamivudine was taken continuously, and liver function was improved gradually. Eight months after surgery, pump repair was conducted for pump wall rupture of Denver tube, and 24 months after surgery, Denver tube was removed due to infection of tissues surrounding the pump wall. After the removal, a small amount of ascites was occasionally present, which could be controlled by intermittent small dose of diuretics. After the 26-months of lamivudine treatment, adefovir dipivoxil was added due to lamivudine resistance, and HBV DNA was controlled below the detection level. At 5 years after surgery, the patient was better and could resume his normal life (Table 1).

\section{Case 2: 20 months of antiviral therapy followed by PVS}

A 64-year-old male patient with 20 years of chronic hepatitis B was admitted to hospital in December, 2005 for cirrhosis with massive ascites for 7 months. HBsAg and anti-HBe were positive, HBV DNA was $2.4 \times 10^{5}$ copies $/ \mathrm{ml}$, CTP score was 11 points and MELD score was 20 points. After admission, the patient was well responsive to lamivudine but his massive ascites could not be treated effectively with routing medical therapy. After 20 months of antiviral therapies, Denver shunt surgery was performed. After surgery, abdominal distension improved significantly, and body weight was reduced by $5 \mathrm{~kg}$. Only a small dose of diuretics was used continuously. Five months later, the septicemia was induced by spontaneous bacterial peritonitis and recovered soon by medical treatment. Currently, lamivudine has been taken over 6.5 years and the Denver shunt is still working. HBV load was controlled below the detection line, liver function and nutritional status were significantly improved, body weight was increased by $8 \mathrm{~kg}$ and only a very small amount of ascites in the pelvic cavity was observed by ultrasound B after diuretics were maintained in low amounts (Table 1).

\section{Case 3: 20 months of PVS followed by antiviral therapy}

A 43-year-old female patient was admitted to hospital for HBV-related cirrhotic ascites for 4 months. Her HBsAg and HBeAg were positive, HBV DNA was positive, abdominal circumference was $80 \mathrm{~cm}$, urinary volume was $750 \mathrm{ml} / \mathrm{d}$, CTP score was 8 points and MELD score was 15 points. The patient was given diuretics, paracentesis, concentrated ascites reinfusion therapy (CART) for one month and achieved poor results. In December, 1998, the Denver shunt was performed. After surgery, urinary volume increased to $1500 \mathrm{ml} / \mathrm{d}$ and ascites disappeared. The ascites recurred due to Denver tube blockage and slipping of the jugular vein stump in November, 1999 and Feburary, 2000. The ascites disappeared after reinsertion of Denver tube. The patient began to take lamivudine in August, 2000, and had a reexamination in May 2012. HBV DNA was $<1 \times 10^{3}$ copies $/ \mathrm{ml}$, liver function test including total bilirubin, ALT, albumin and prothrombin time was normal, no peritoneal effusion could be seen by ultrasound B, CTP score was 5 points, MELD score was 6.5 points, and the body weight increased by $11 \mathrm{~kg}$. The Denver tube had been placed for more than 13 years and could be removed (Table 1).

\section{DISCUSSION}

For patients with refractory ascites, current medical therapies include serial therapeutic paracenteses, transjugular intrahepatic portosystemic shunt (TIPS) and liver transplantation, etc. It is known that serial therapeutic paracenteses are effective in controlling ascites, but may induce electrolyte disturbance and increase the risk of hepatic encephalopathy (HE) and other complications. TIPS can significantly reduce portosystemic pressure, but although its therapeutic value for ascites has been demonstrated by various studies, it is invasiveness and may induce severe HE. ${ }^{3}$ Liver transplantation is the most effective therapy for refractory ascites, but can not be developed rapidly for its high cost and the shortage of donor liver.

The AASLD Guideline in 2009 for management of adult patients with cirrhotic ascites maitains that PVS should be considered for patients with refractory ascites who are not candidates for paracenteses, 
Table 1. Brief conditions of PVS combined with antiviral therapy for HBV-related cirrhosis with refractory ascites in 3 cases

\begin{tabular}{|c|c|c|c|}
\hline Program & Case 1 & Case 2 & Case 3 \\
\hline Lamivudine (months) & 80 & 92 & 156 \\
\hline Adefovir dipivoxil added (months) & 42 & 0 & 0 \\
\hline Timing of PVS & 2 months after antiviral therapy & 20 months after antiviral therapy & 20 months before antiviral therapy \\
\hline \multicolumn{4}{|l|}{ HBV DNA (copies/ml) } \\
\hline Baseline & $2.39 \times 10^{5}$ & $2.4 \times 10^{5}$ & Positive (qualitative method) \\
\hline Last follow-up & $<1.0 \times 10^{3}$ & $<1.0 \times 10^{3}$ & $<1.0 \times 10^{3}$ \\
\hline \multicolumn{4}{|l|}{ CTP score (grading) } \\
\hline Baseline & 11 (grade C) & 11 (grade C) & 8 (grade B) \\
\hline Last follow-up & 8 (grade B) & 8 (grade B) & $5($ grade A) \\
\hline \multicolumn{4}{|l|}{ MELD score } \\
\hline Baseline & 14.8 & 21.5 & 18.1 \\
\hline Last follow-up & 13.1 & 13.3 & 6.5 \\
\hline Survival time (year) & 6.7 & 7.7 & 14.7 \\
\hline State of ascites & Occasional small amount & Small amount & No \\
\hline State of Denver tube & Removed & Still working & Not required, selective removal \\
\hline Diuretics & Intermittently & Maintained in small amount & Withdrawn for 4 years \\
\hline
\end{tabular}

Notes: PVS: peritoneovenous shunt.

transplant, or TIPS. ${ }^{4}$ The design of PVS tube was inspired by the Holter valves used for hydrocephalus in brain surgery and was found to be effective for cirrhotic ascites. ${ }^{5}$ In 1960s, Hyde tube enables ascites to bypass into the veins via the pressure-driven oneway valve. LeVeen et al reported PVS was performed by a tubule with a special small lumen for refractory ascites in $1974 .^{6-7}$ However, both methods were used rarely due to high rate of shunt obstruction. In the 1980s, the use of Denver tube with dual valves improved the methods described above. It is composed of medical silicone with great biocompatibility, with peritoneal catheter with multiple side holes on one end, a heparinized venous catheter on the other end, and a flexible bypass chamber in the middle, with two one-way (from abdominal cavity to the vein) valves inside the chamber. PVS using Denver tube enables ascites to continuously bypass into systemic circulation, leading to an increase in cardiac output, expanded plasma volume, and decreased the secretion of aldosterone and antidiuretic hormone (ADH), thereby reducing ascites and albumin input and improving the quality of life. ${ }^{8-10}$ In addition, Denver tube with dual valves can control flow rate and reduce heart load.

For three cases of decompensated HBV-related cirrhosis with refractory ascites, PVS using Denver tube was combined with the lamivudine for antiviral treatment before and after and achieved a satisfactory long-term effect.

In case 1, CTP score was 11 points (grade C) at consultation, good virologic response to the antiviral therapy was shown, massive ascites remained, and poor therapeutic effect was achieved, all of which point to refractory ascites. After placement of Denver tube, ascites were alleviated significantly, and hepatic function and nutritional status were improved. Two years after surgey, Denver tube was removed, and only a small amount of ascites remained, which could be controlled by routine diuretics.

For patients with refractory ascites, even with stabilized liver function after antiviral therapy, ascites might not be improved. At this time, antiviral drugs combined with Denver tube in PVS showed its advantages. In case 2 , after 20 months of treatment by lamivudine, although good virologic response to the antiviral therapy was shown, refractory ascites were not improved. However, after PVS, ascites were controlled rapidly, plasma albumin levels were significantly increased, and nutritional status was improved. Now, it was 6 years after surgery. The Denver tube remained function in situ, and only a very small amount of ascites in the pelvic cavity was observed by ultrasound $\mathrm{B}$.

In case 3, the patient was present with great abdominal distension and was quite thin. After placement of Denver tube, ascites were significantly improved, but liver function was repeatedly abnormal. 20 months after surgery, antiviral therapy was maintained for more than 13 years. Now liver function was completely normal, ascites disappeared, body weight increased by $11 \mathrm{~kg}$. The patient could resume his normal life and work.

PVS was progressively ruled out during the 
last decade because it has not been shown by prospective trials to significantly prolong patients' survival. Dumortier reported that the control of refractory ascites by PVS in patients waiting for liver transplantation could avoid short-term complications of ascites before curative treatment of liver cirrhosis. ${ }^{11}$ Our results also suggested that PVS might be beneficial to HBV-related cirrhotic patients with refractory ascites receiving antiviral treatment. The Denver tube in PVS could be used as an adjuvant method to antiviral drugs for decompensated HBVrelated cirrhosis with refractory ascites to help the patients get over and reap the full benefits and maximize efficacy of antiviral treatment.

\section{REFERENCES}

1. Arroyo V, Gines P, Gerbes AL, Dudley FJ, Gentilini P, Laffi G, et al. Definition and diagnostic criteria of refractory ascites and hepatorenal syndrome in cirrhosis. International Ascites Club. Hepatology 1996; 23:164-176.

2. Fontana RJ, Hann HW, Perrillo RP, Vierling JM, Wright T, Rakela J, et al. Determinants of early mortality in patients with decompensated chronic hepatitis B treated with antiviral therapy.
Gastroenterology 2002; 123:719-727.

3. Thuluvath PJ, Bal JS, Mitchell S, Lund G, Venbrux A. TIPS for management of refractory ascites: response and survival are both unpredictable. Dig Dis Sci 2003; 48: 542-550.

4. Runyon BA. AASLD Practice Guidelines Committee. Management of adult patients with ascites due to cirrhosis: an update. Hepatology 2009; 49: 2087-2107.

5. Smith AN. Peritoneocaval shunt with a Holter valve in the treatment of ascites. Lancet 1962; 31: 671-672.

6. Hyde GL, Dillon M, Bivins BA. Peritoneal venous shunting for ascites: a 15-year perspective. Am Surg 1982; 48:123-127.

7. Leveen HH, Christoudias G, Ip M, Luft R, Falk G, Grosberg S. Peritoneo-venous shunting for ascites. Ann Surg 1974; 180:580-590.

8. Greig PD, Blendis LM, Langer B, Taylor BR, Colapinto RF. The renal and hemodynamic effects of the peritoneovenous shunt: Long term effect. Gastroenterology 1981;80:119-125.

9. Reznick RK, Langer B, Taylor BR, Seif S, Blendis LM. Hyponatremia and $\mathrm{ADH}$ secretion in patients with refractory hepatic ascites undergoing peritoneovennous shunting. Gastroenterology 1983;84:713-718.

10. Blendis LM, Sole MJ, Campbell P, Lossing AG, Greig PD, Taylor BR, et al. The effects of peritoneovenous shunting on catecholamine metabolism in patients with hepatic ascites. Hepatology 1987; 7:143-148.

11. Dumortier J, Pianta E, Le DY, Bernard P, Bouffard Y, Boucaud C, et al. Peritoneovenous shunt as a bridge to liver transplantation. Am J Transplant 2005;5(8):1886-1892. 